\title{
Soil Biodegradation of PLA/CNW Nanocomposites Modified with Ethylene Oxide Derivatives
}

\author{
Gelsoneide da Silva Gois ${ }^{a}$, Michelle Félix de Andrade ${ }^{a}$, Sônia Maria Silva Garcia ${ }^{a}$, \\ Glória Maria Vinhas ${ }^{b}$, Amélia S. F. Santos ${ }^{c}$, Eliton S. Medeiros ${ }^{c}$, Juliano E. Oliveirad, \\ Yêda Medeiros Bastos de Almeida ${ }^{b *}$ \\ ${ }^{a}$ Centro de Ciências Exatas e da Natureza, Universidade Federal de Pernambuco - UFPE, Av. Prof. \\ Moraes Rego, 1235, Cidade Universitária, 50670-901, Recife, PE, Brasil \\ ${ }^{b}$ Departamento de Engenharia Química, Universidade Federal de Pernambuco - UFPE, Av. Prof. \\ Moraes Rego, 1235, Cidade Universitária, 50670-901, Recife, PE, Brasil \\ ${ }^{c}$ Departamento de Engenharia de Materiais, Universidade Federal da Paraíba - UFPB, Cidade \\ Universitária, s/n, Castelo Branco, 58051-900, Paraíba, PB, Brasil \\ ${ }^{d}$ Departamento de Engenharia, Universidade Federal de Lavras - UFLA, Caixa Postal 3037, \\ 37200-000, Lavras, MG, Brasil
}

Received: December 12, 2016; Revised: November 18, 2017; Accepted: January 25, 2018

\begin{abstract}
Due to its ester bonds, poly(lactic acid) (PLA) undergoes biodegradation in humid environments, attracting market attention. The goal of this work was to observe the biodegradation in garden soil of PLA nanocomposites with neat (PLA/CNW) and surfactant modified cellulose nanowhiskers (PLA/ $\mathrm{CNW} / \mathrm{S}$ ). Three types of surfactants were tested: poly(ethylene glycol) monooleate (PEGMONO) and poly(ethylene glycol) with molecular weight of 300 and $1000 \mathrm{Da}$. The films were obtained by solution casting, cut in strips of $(2 \times 2) \mathrm{cm}$ and buried in garden soil, monitoring the temperature and humidity. After 90, 120 and 150 days changes were observed in the films by visual inspection, polarized light microscopy, thermogravimetric analysis (TGA) and Fourier transform infrared spectroscopy (FTIR). The results showed that the addition of surfactant favored the biodegradation of nanocomposites and that PLA/CNW/PEG1000 showed the fastest biodegradation rate.
\end{abstract}

Keywords: biodegradation, PLA, CNW, surfactant.

\section{Introduction}

The environment is suffering serious damage due to the overuse of natural resources and the growth of urban centers. The increase in the generation of municipal solid waste (MSW) is among the main environmental problems experienced in the contemporary world. In this context, the growing use of petroleum based plastics for various applications, together with their non-biodegradable nature account for a significant part of this impact, a problem aggravated by the lack of adequate waste disposal sites ${ }^{1,2}$.

A solution to minimize problems associated with the accumulation of plastics waste is the use of biodegradable polymers, which are susceptible to degradation caused by the action of microorganisms, leading to fragmentation, followed by mineralization (formation of carbon dioxide and/ or methane, water and biomass) $)^{3}$. Cellulose nanowhiskers $(\mathrm{CNW})$ together with biodegradable polymers from renewable resources attract attention from the scientific community for having a new perspective on a future scenario in replacing non-degradable plastics.

*e-mail: yeda@ufpe.br
Poly(lactic acid) (PLA), a type of biodegradable polymer, appears as a thermoplastic synthesized from renewable resources and with applications in several areas. According to literature ${ }^{4,5}$, when the PLA product is correctly discarded, it undergoes hydrolysis, being converted into harmless natural products. The biodegradation time of PLA in the environment is in the order of six months to two years compared to 500 to 1000 years for conventional plastics, such as polystyrene and polyethylene ${ }^{4}$.

The use of cellulose nanowhiskers (CNW) occurs as a nanoreinforcement for the PLA matrix. The CNW consist of cellulose naonocrystals with high crystallinity, high surface area and nanometric dimensions. These $\mathrm{CNW}$ are extracted from renewable resources, are biodegradable, have low density and have been largely used to improve polymer performance ${ }^{6,7}$. Other authors ${ }^{7,8,9}$ evaluated mechanical and thermal properties of PLA/CNW nanocomposites and achieved improvements in the modulus of elasticity and glass transition temperature of neat PLA. Fortunatiet al. ${ }^{9}$, for example, obtained an increase of $21 \%$ and $55 \%$ in the modulus of elasticity for PLA/CNW in proportions of 99/1 and 97/3, respectively, as well as an increase in the glass transition temperature. Nevertheless, a reduction in tensile 
stress at break is usually observed due to CNW tendency to agglomerate and act as points of stress concentrations in nonpolar polymer matrices ${ }^{10,11,12}$.

Several works ${ }^{8,11,12,13,14}$ have been using surfactants as an alternative to improve $\mathrm{CNW}$ dispersion in nonpolar polymer matrices. The preparation consists of an aqueous suspension of $\mathrm{CNW}$ with surfactant, followed by freeze drying. The addition of surfactant may promote electrostatic repulsion or steric hindrance among particles, inhibiting their agglomeration into flakes during the freeze-drying process due to the strong hydrogen bonds. The use of nonionic surfactant for CNW dispersion in polymer matrices was practically unexplored.

The aim of this study was to evaluate the biodegradation of PLA nanocomposites with neat CNW (PLA/CNW) and surfactant modified CNW (PLA/CNW/S). Three different types of ethylene oxide derivatives were evaluated, taking into account a fixed amount of CNW and CNW:surfactant ratio. The biodegradation tests were performed for a period of 90, 120 and 150 days, using garden soil.

\section{Materials and Methods}

\subsection{Materials}

Poly(lactic acid) (PLA), Ingeo 3251D, with melt flow index (MFI) of $80 \mathrm{~g} .10 \mathrm{~min}^{-1}\left(210^{\circ} \mathrm{C}, 2.16 \mathrm{~kg}\right)$ was supplied by Cargil S.A. Garden soil and commercial cotton linters, used as a source of cellulose, were purchased from a local market. Analytical grade sulfuric acid $\left(\mathrm{H}_{2} \mathrm{SO}_{4}, 95-97 \%\right.$, Química Moderna, Brazil) and chloroform (VETEC, Brazil) were used without further purification.

Three types of non-ionic surfactants containing poly(ethylene glycol) units were used in this study: poly(ethylene glycol) 300 (PEG300) (molecular weight from 285 to 315 Da and hydrophilic-lipophilic balance (HLB) of 9-12), poly(ethylene glycol) 1000 (PEG1000) (molecular weight from 900 to 1050 Da and HLB of 11-12), both purchased from Oxiteno $\mathrm{SA}$, and poly(ethylene glycol) monooleate (PEGMONO) (molecular weight of $860 \mathrm{Da}$ and HLB lower than 10) purchased from Sigma Aldrich.

\subsection{Preparation of Cellulose Nanowhiskers}

The acid hydrolysis was carried out according to the method reported by Dong et al. ${ }^{15}$ that consists of $5 \mathrm{wt} \%$ of cotton linters addition in $64 \mathrm{vol} \%$ sulfuric acid solution at $45^{\circ} \mathrm{C}$ for $60 \mathrm{~min}$ under vigorous mechanical stirring. Then, the excess of acid was removed by repeated centrifugation cycles at $3000 \mathrm{rpm}$ for $15 \mathrm{~min}$ (Centerium Scientific K3 Series). Afterwards, the resulting dispersion was dialyzed against running water until a $\mathrm{pH}$ of 7 was reached. Part of the dialyzed aqueous dispersion was stored in a freezer, and the other part was diluted to $4 \mathrm{mg} \cdot \mathrm{mL}^{-1}$ in deionized water and freeze-dried in an LB 300TT equipment to obtain the neat $\mathrm{CNW}$ powder. The freeze-dried sample was stored in a desiccator at room temperature.
Surfactant modified CNW (CNW/S) were prepared by adding each surfactant to the aqueous dispersion of CNW at a 1:1 weight ratio ${ }^{12,16,17}$, based on dry mass of nanowhiskers. For adsorption to occur, dispersions were vigorously mixed using an Ultra Turrax (IKA T18 Basic) at $7000 \mathrm{rpm}$ for 30 s. The obtained CNW/S dispersions were freeze-dried (LB 300TT) and stored similarly to neat CNW. The three CNW samples containing surfactants were labeled as: $\mathrm{CNW} /$ PEG300, CNW/PEG1000 and CNW/PEGMONO.

The CNW had an average length and diameter of (209 $\pm 8) \mathrm{nm}$ and $(20 \pm 1) \mathrm{nm}$, respectively, and aspect ratio of $(10 \pm 0.5) \mathrm{nm}$, as determined by atomic force microscopy (unpublished data). Similar results were found by Lizundia et al. ${ }^{18}$

\subsection{Preparation of PLA/CNW Nanocomposites Films}

The films were prepared by solution casting method. Dispersions of neat CNW and CNW/S (1:1) in chloroform, prepared with nanowhiskers content adjusted to obtain nanocomposites with $3 \mathrm{wt} \%$ of $\mathrm{CNW}$, were magnetically stirred and further, mixed with the previously prepared 10 $\mathrm{wt} \%$ solution of PLA in chloroform and stirred for about 30 min. The neat PLA, PLA/CNW and PLA/CNW/S dispersions were poured onto glass Petri dishes greased with silicon $(\varnothing$ $15 \mathrm{~cm}$ ) and left to evaporate for $48 \mathrm{~h}$ at room temperature. The concentration was chosen based on the literature reports 9,16,17,19. The PLA/CNW and PLA/CNW/S films presented a non-uniform dispersion with small agglomerates visible to the naked eye. This behavior is related to the weak interaction between CNW and PLA matrix and also, due to irreversible aggregation of CNW during the freeze-drying process of suspensions ${ }^{12,16,17,20}$.

\subsection{Biodegradation test}

Tests were carried out according to ASTM G 160-03. The garden soil used has a varied microbial flora with bacteria, fungi, yeasts and presence of sporulated bacilli, confirmed by plate colony-counting method ${ }^{21,22}$. In order to prove the microbial activity of the garden soil, tensile tests were performed on samples of cotton cloth to prove a tensile strength loss of at least $50 \%$ after burying them in the soil for five days.

Thus, after evaluating the adequacy of the garden soil, the PLA, PLA/CNW and PLA/CNW/PEG300, PLA/ CNW/PEG1000 and PLA/CNW/PEGMONO films cut to approximately $(2 \times 2) \mathrm{cm}$ were buried for $90,120,150$ and 180 days ( 180 days being analyzed only visually) ${ }^{23}$. During the test period, soil temperature and moisture were monitored weekly. The soil temperature remained around $(29 \pm 0.6){ }^{\circ} \mathrm{C}$ and the soil moisture content was adjusted to $(28 \pm 6) \%$. The soil moisture content was determined by measuring the weight loss of soil upon drying it for $24 \mathrm{~h}$ at $105^{\circ} \mathrm{C}$. At the end of each exposure period, the specimens were removed 
from the soil bed and tested according to respective test method. For visual evaluation, the material is rinsed under a stream of tap water while gently rubbing between fingers to remove soil and dried at room conditions.

\subsection{Characterizations}

The films were characterized before and after each exposure period in biodegradation test by polarized light microscope (Leica ICC 50), using magnification up to 40x. Thermogravimetric analysis (TGA) was performed using a Perkin Elmer simultaneous thermal analyzer STA6000. The samples were heated from room temperature to $700^{\circ} \mathrm{C}$ at 10 ${ }^{\circ} \mathrm{C} \cdot \mathrm{min}^{-1}$ in a nitrogen flow rate of $20 \mathrm{~mL} \cdot \mathrm{min}^{-1}$. The samples were analyzed in a Bruker Tensor 27 FTIR spectrophotometer, using 16 scans with resolution of $4 \mathrm{~cm}^{-1}$ and interval of $2 \mathrm{~cm}^{-1}$. Analyses were performed in the attenuated total reflectance mode (ATR) by direct analysis of film on ZnSe crystal. The FTIR spectra were baseline-corrected and ATR corrected. The carbonyl index was calculated by the ratio of the peak intensity at $1748 \mathrm{~cm}^{-1}$ to the reference peak at $1451 \mathrm{~cm}^{-1}$.

\section{Results and Discussion}

\subsection{Soil microbial and standard microbial activity (ASTM G160-03)}

Fungi and bacteria produce enzymes known as hydrolases that catalyze hydrolysis of polyesters. The analyzed soil sample had a bacterial population of $606 \mathrm{CFU}$ and fungi greater than $1000 \mathrm{CFU}$. Among the bacteria, there are green bacteria stick-shaped that produce spores (Figure 1). These species survive under unfavorable environmental conditions, such as nutrient or water shortages, which assure the continuity of the biodegradation process.

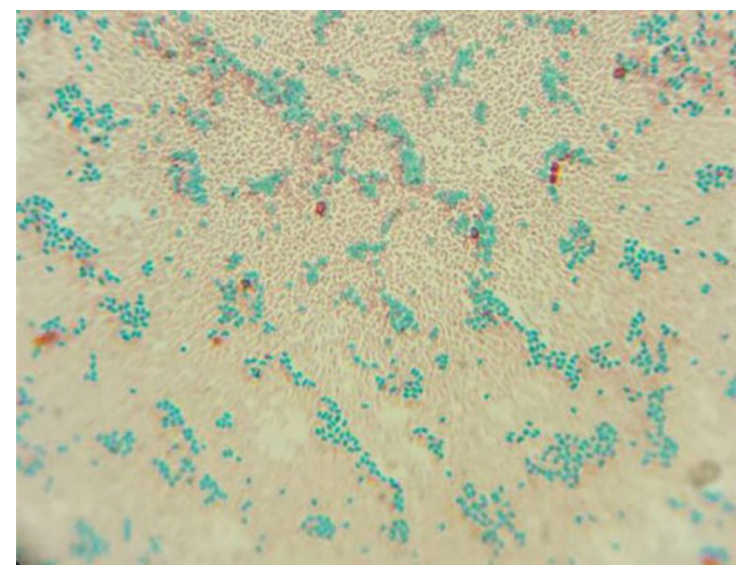

Figure 1. Image of bacteria that produce spores in soil.

By the tensile test, the cotton specimens before and after 05 five days of exposure to the garden soil presented a tensile strength of $(4.3 \pm 0.6) \mathrm{MPa}$ and $(2.0 \pm 0.7) \mathrm{MPa}$, respectively. Therefore, a reduction of tensile strength by about $50 \%$ is achieved, which is in accordance with the standard requirement.

\subsection{Visual inspection and polarized light microscopy}

Figure 2 shows the images of neat PLA, PLA/CNW, PLA/CNW/PEG300, PLA/CNW/PEG1000 and PLA/CNW/ PEGMONO films before and after 150 days of exposure to garden soil. It is noteworthy that PLA has a slow rate of disintegration compared to other biodegradable polyesters. Rudnik and Briassoulis ${ }^{24}$ explain that microorganisms that degrade PLA are not easily found in natural environments, thus making it less susceptible to microbial attack.

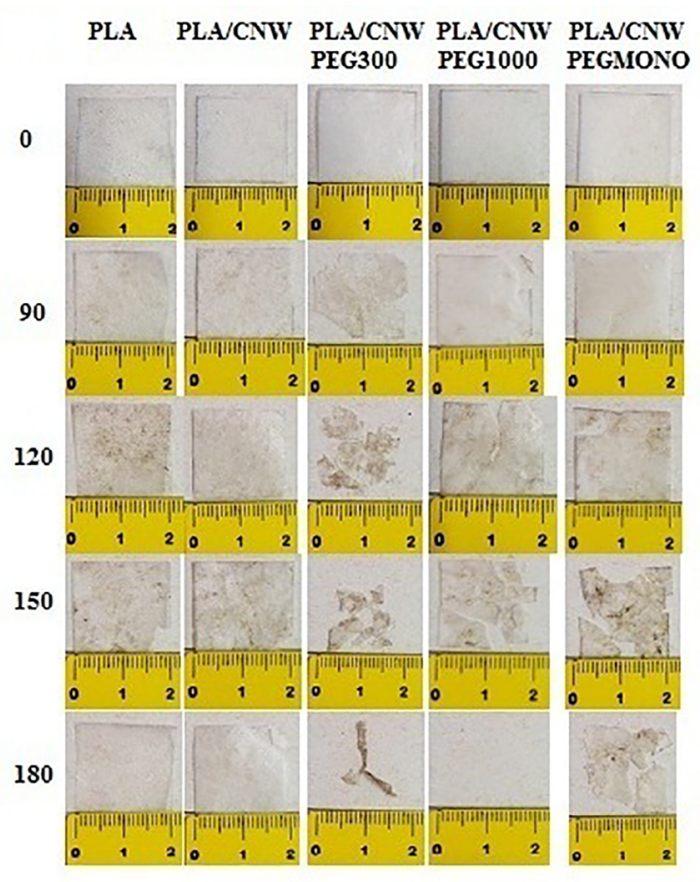

Figure 2. Visual appearance of PLA, PLA/CNW and PLA/CNW/S films before and after 90,120,150 e 180 days of exposure to garden soil.

Among samples, the degradation of the PLA/CNW/ PEG300, PLA/CNW/PEG1000 and PLA/CNW/PEGMONO nanocomposites were more noticeable than PLA/CNW and neat PLA, because they presented greater brittleness, resulting in fragmentation of the films. According to these results, surfactant accelerates degradation of polymer matrix and the PLA/CNW/PEG1000 presented the fastest disintegration rate, since it was not possible to visualize residues within 180 days.

The polarized light micrographs of the films showed that PLA/CNW and PLA/CNW/S films after degradation showed degradation points (Figure 3) more evident than observed in neat PLA. According to Haque et $a l .{ }^{24}$, the holes 
on the surface of samples can be formed by the degradation of the interspherulitic amorphous phase regions or between the crystalline regions due to enzymatic degradation ${ }^{25,26}$. The nucleating efffect of $\mathrm{CNW}$ and $\mathrm{CNW} / \mathrm{S}$ on the PLA nanocomposites ${ }^{11,20,27}$ probably contributed to this behavior. Furthermore, the surfactant itself also enhances the disintegration rate of PLA/CNW/S nanocomposites in the composting process, because it induces the formation of a porous structure in the PLA/CNW/S nanocomposites and increases nanocomposites accessibility to water and microorganisms ${ }^{25,28}$.

Also changes in surface polarity of composite by the use of $\mathrm{CNW} / \mathrm{S}$ probably contributed to these results, since an increase on surface polarity catalyze the hydrolysis process, leading to higher disintegration rates ${ }^{25}$. Similar results were achieved for PLA/CNW/S nanocomposites prepared with a commercial cationic surfactant (Beycostat A B09 - CECCA S.A) and were attributed to their relative higher hydrophilicity compared to PLA ${ }^{20}$.

After 150 days of biodegradation, some degradation points (yellow circles in Figure 3) are more evident in $\mathrm{PLA} / \mathrm{CNW} / \mathrm{S}$ samples than in neat PLA and PLA/CNW, again proving that the garden soil was adequate to perform biodegradation tests.

\subsection{Thermogravimetric Analysis (TGA)}

By comparing the initial thermal decomposition temperature (Tonset) and temperature at the maximum rate of weight loss (Tmax) of neat PLA with PLA/CNW (Table 1), the addition of $\mathrm{CNW}$ did not significantly change the degradation temperature values of the neat PLA. However, the addition of surfactants reduced the degradation temperature values of neat PLA. Furthermore, all samples exposed to soil showed a decrease in the onset temperature (Tonset) and temperature at the maximum rate of weight loss (Tmax) after 150 days of soil exposure, as has already been found by Arrieta et $a l{ }^{26}$. In the present study, the most significant difference was observed for PLA/CNW/PEG1000 with a decrease of $8 \%$ in Tonset after 150 days of soil exposure, which confirms the previous results of visual inspection.

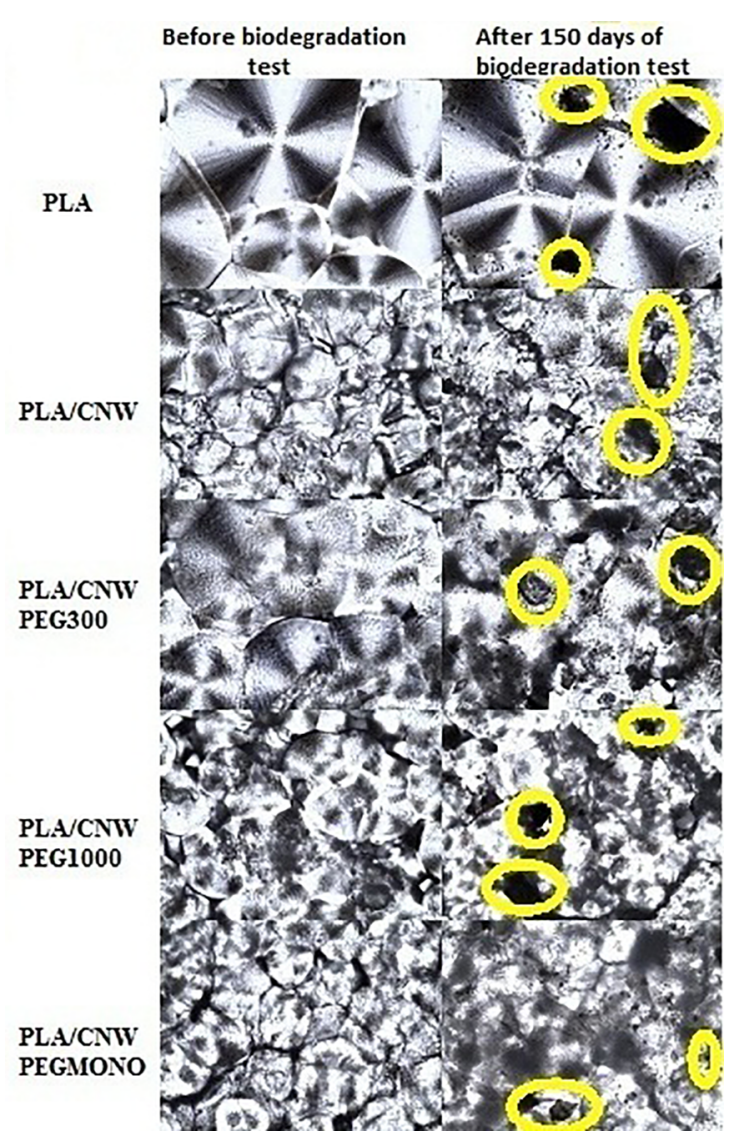

Figure 3. Optical micrographs of these films before and after 150 days of soil biodegradation.

\subsection{Fourier transform infrared spectroscopy (FTIR)}

Fourier transform infrared spectroscopy was used to evaluate the chemical modifications that occur on films surface. The spectra of all films before and after biodegradation test in soil are similar and there is no shift on characteristic bands or formation of new bands. However, the carbonyl index of films after being buried in soil for 90, 120 and 150 days increased, as summarized in Table 2. That increment in the intensity of the carbonyl bands is attributed to an increase in terminal carboxyl end groups due to hydrolytic degradation under biodegradation test ${ }^{24,25}$.

Table 1. Values of the onset degradation temperature (Tonset) and temperature at the maximum rate of weight loss (Tmax) for neat PLA, $\mathrm{PLA} / \mathrm{CNW}$ and PLA/CNW/S nanocomposites at different exposure times in soil.

\begin{tabular}{|c|c|c|c|c|c|c|c|c|c|c|}
\hline \multirow{3}{*}{$\begin{array}{c}\text { Time of } \\
\text { Biodegradation } \\
\text { (days) }\end{array}$} & \multicolumn{10}{|c|}{ Temperature $\left({ }^{\circ} \mathrm{C}\right)$} \\
\hline & \multicolumn{2}{|c|}{ PLA } & \multicolumn{2}{|c|}{$\mathrm{PLA} / \mathrm{CNW}$} & \multicolumn{2}{|c|}{$\begin{array}{l}\text { PLA/CNW } \\
\text { PEG300 }\end{array}$} & \multicolumn{2}{|c|}{$\begin{array}{l}\text { PLA/CNW } \\
\text { PEG1000 }\end{array}$} & \multicolumn{2}{|c|}{$\begin{array}{l}\text { PLA/CNW } \\
\text { PEGMONO }\end{array}$} \\
\hline & Tonset & Tmax & Tonset & $\operatorname{Tmax}$ & Tonset & Tmax & Tonset & Tmax & Tonset & Tmax \\
\hline 0 & 335 & 359 & 335 & 361 & 330 & 357 & 320 & 361 & 328 & 361 \\
\hline 90 & 327 & 355 & 327 & 349 & 321 & 352 & 307 & 350 & 326 & 355 \\
\hline 120 & 324 & 356 & 318 & 354 & 306 & 345 & 300 & 348 & 316 & 349 \\
\hline 150 & 323 & 351 & 311 & 350 & 301 & 346 & 296 & 349 & 304 & 343 \\
\hline
\end{tabular}


Table 2. Values of carbonyl index of neat PLA and PLA nanocomposites films before and after different exposure times in soil.

\begin{tabular}{cccccc}
\hline Days & PLA & PLA/CNW & $\begin{array}{c}\text { PLA/CNW/ } \\
\text { PEG300 }\end{array}$ & $\begin{array}{c}\text { PLA/CNW/ } \\
\text { PEG1000 }\end{array}$ & $\begin{array}{c}\text { PLA/CNW/ } \\
\text { PEGMONO }\end{array}$ \\
\hline 0 & 2.80 & 2.92 & 2.47 & 2.63 & 2.41 \\
90 & 2.58 & 2.04 & 2.19 & 2.38 & 2.16 \\
120 & 3.36 & 5.12 & 2.98 & 3.40 & 3.30 \\
150 & 3.19 & 3.59 & 3.85 & 3.55 & 3.59 \\
\hline
\end{tabular}

\section{Conclusions}

According to obtained results, the garden soil was suitable for biodegradation tests of neat PLA and PLA nanocomposites, confirming the action of microorganisms on the substrates. Besides that, the use of the surfactant modified $\mathrm{CNW}$ accelerated the biodegradation rate of nanocomposites, resulting in a greater disintegrability of these films after the biodegradation test in soil. Among ethylene oxide derivatives, PEG 1000 showed the fastest disintegration rate.

\section{Acknowledgements}

The authors gratefully acknowledge National Foundation for Science and Technology Development (CNPq) and Science and Technology Foundation of Pernambuco State (FACEPE) for their financial support of this study. Thanks are also to Biomaterials and Biosystems Laboratory (LAMAB/UFPB) and Polymer Materials and Characterization Laboratory (LMPC/UFPE) for sample characterizations.

\section{References}

1. Lima RMR, Romeiro Filho E. The ergonomics analysis contribution for the product project directed towards recycling. Production. 2003;13(2):82-87. DOI: 10.1590/S0103-65132003000200008.

2. Franchetti SMM, Marconato JC. Biodegradable polymers - a partial way for decreasing the amount of plastic waste. Química Nova. 2006;29(4):811-816. DOI: 10.1590/S010040422006000400031.

3. Suryanegara L, Nakagaito AN, Yano H. The effect of crystallization of PLA on the thermal and mechanical properties of microfibrillated cellulose-reinforced PLA composites. Composites Science and Technology. 2009;69(7-8):1187-1192. DOI: 10.1016/j.compscitech.2009.02.022.

4. Garlotta D. Literature review of poly(lactic acid). Journal of Polymers and the Environment. 2001;9(2):63-84. DOI: 1023/A:1020200822435

5. Lemos AL, Martins RM. Development and Characterization of Polymeric Composites Based on Poly (Lactic Acid) and Natural Fibers. Polímeros Ciência e Tecnologia. 2014;24:190-197. DOI: 10.4322/polimeros.2014.047.

6. Morelli CL, Marconcini JM, Pereira FV, Bretas RES, Branciforti MC. Extraction and Characterization of Cellulose Nanowhiskers from Balsa Wood. Macromolecular Symposia. 2012;319(1):191195. DOI: 10.1002/masy.201100158.
7. Kamal MR, Khoshkava V. Effect of cellulose nanocrystals (CNC) on rheological and mechanical properties and crystallization behavior of PLA/CNC nanocomposites. Carbohydrate Polymers. 2015;123:105-114. DOI: 10.1016/j.carbpol.2015.01.012.

8. Petersson L, Kvien I, Oksman K. Structure and thermal properties of poly(lactic acid)/cellulose whiskers nanocomposite materials. Composites Science and Technology. 2007;67(11-12):25352544. DOI: 10.1016/j.compscitech.2006.12.012.

9. Fortunati E, Luzi F, Puglia D, Dominici F, Santulli C, Kenny $\mathrm{JM}$, et al. Investigation of thermo-mechanical, chemical and degradative properties of PLA-limonene films reinforced with cellulose nanocrystals extracted from Phormium tenax leaves. European Polymer Journal. 2014;56:77-91. DOI: 10.1016/j. eurpolymj.2014.03.030.

10. Mathew AP, Oksman K, Sain M. Mechanical properties of biodegradable composites from poly lactic acid (PLA) and microcrystalline cellulose (MCC). Journal of Applied Polymer Science. 2005;97(5):2014-2025. DOI: 10.1002/app.21779.

11. Fortunati E, Armentano I, Zhou Q, Iannoni A, Saino E, Visai L, et al. Multifunctional bionanocomposite films of poly(lactic acid), cellulose nanocrystals and silver nanoparticles. Carbohydrate Polymers. 2012;87(2):1596-1605. DOI: 10.1016/j. carbpol.2011.09.066.

12. Emami Z, Meng Q, Pircheraghi G, Manas-Zloczower I. Use of surfactants in cellulose nanowhisker/epoxy nanocomposites: effect on filler dispersion and system properties. Cellulose. 2015;22(5):3161-3176. DOI: 10.1007/s10570-015-0728-6.

13. Heux L, Chauve G, Bonini C. Nonflocculating and ChiralNematic Self-ordering of Cellulose Microcrystals Suspensions in Nonpolar Solvents. Langmuir. 2000;16(21):8210-8212. DOI: 10.1021/la9913957.

14. Fortunati E, Armentano I, Zhou Q, Puglia D, Terenzi A, Berglund LA, et al. Microstructure and nonisothermal cold crystallization of PLA composites based on silver nanoparticles and nanocrystalline cellulose. Polymer Degradation and Stability. 2012;97(10):20272036. DOI: 10.1016/j.polymdegradstab.2012.03.027.

15. Dong XM, Revol JF, Gray DG. Effect of microcrystallite preparation conditions on the formation of colloid crystals of celulose. Cellulose. 1998;5(1):19-32. DOI: 10.1023/A:1009260511939.

16. Bondeson D, Oksman K. Dispersion and characteristics of surfactant modified cellulose whiskers nanocomposites. Composite Interfaces. 2007;14(7-9):617-630. DOI: 10.1163/156855407782106519.

17. Kim J, Montero G, Habibi Y, Hinestroza JP, Genzer J, Argyropoulos DS, et al. Dispersion of cellulose crystallites by nonionic surfactants in a hydrophobic polymer matrix. 
Polymer Engineering and Science. 2009;49(10):2054-2061. DOI: $10.1002 /$ pen.21417.

18. Lizundia E, Vilas JL, León LM. Crystallization, structural relaxation and thermal degradation in Poly(l-lactide)/cellulose nanocrystal renewable nanocomposites. Carbohydrate Polymers. 2015;123:256-265. DOI: 10.1016/j.carbpol.2015.01.054.

19. Silviya EK, Unnikrishnan G, Varghese S, Guthrie JT. Surfactant effects on poly(ethylene-co-vinyl acetate)/cellulose composites. Composites Part B: Engineering. 2013;47:137-144. DOI: 10.1016/j.compositesb.2012.10.009.

20. Arrieta MP, Fortunati E, Dominici F, Rayón E, López J, Kenny JM. PLA-PHB/cellulose based films: Mechanical, barrier and disintegration properties. Polymer Degradation and Stability. 2014;107:139-149. DOI: 10.1016/j.polymdegradstab.2014.05.010.

21. Li Z, Hu X, Shi J, Zou X, Huang X, Zhou X,et al. Bacteria counting method based on polyaniline/bacteria thin film. Biosensors and Bioelectronics. 2016;81:75-79. DOI: 10.1016/j. bios.2016.02.022.

22. Szabo JG, Meiners G, Heckman L, Rice EW, Hall J. Decontamination of Bacillus spores adhered to iron and cement mortar drinking water infrastructure in a model system using disinfectants. Journal of Environmental Management. 2017;187:1-7. DOI: 10.1016/j.jenvman.2016.11.024.

23. Arrieta MP, López J, López D, Kenny JM, Peponi L. Development of flexible materials based on plasticized electrospun PLA-PHB blends: structural, thermal, mechanical and disintegration properties. European Polymer Journal. 2015;73:433-446. DOI: 10.1016/j.eurpolymj.2015.10.036.

24. Luzi F, Fortunati E, Puglia D, Petrucci R, Kenny JM, Torre L. Study of disintegrability in compost and enzymatic degradation of PLA and PLA nanocomposites reinforced with cellulose nanocrystals extracted from Posidonia Oceanica. Polymer Degradation and Stability. 2015;121:105-115. DOI: 10.1016/j. polymdegradstab.2015.08.016.

25. Haque MM, Puglia D, Fortunati E, Pracella M. Effect of reactive functionalization on properties and degradability of poly(lactic acid)/poly(vinyl acetate) nanocomposites with cellulose nanocrystals. Reactive and Functional Polymers. 2017;110:1-9. DOI: 10.1016/j.reactfunctpolym.2016.11.003.

26. Rudnik E, Briassoulis D. Degradation behaviour of poly(lactic acid) films and fibres in soil under Mediterranean field conditions and laboratory simulations testing. Industrial Crops and Products. 2011;33(3):648-658. DOI: 10.1016/j.indcrop.2010.12.031.

27. Arrieta MP, Fortunati E, Dominici F, Rayón E, López J, Kenny JM. Multifunctional PLA-PHB/cellulose nanocrystal films: Processing, structural and thermal properties. Carbohydrate Polymers. 2014;107(1):16-24. DOI: 10.1016/j.carbpol.2014.02.044.

28. Aulwar U, Awasthi RS. Production of Biosurfactant and their Role in Bioremediation. Journal of Ecosystem \& Ecography. 2016;6(3):202. DOI: 10.4172/2157-7625.1000202. 